\title{
Talking about the Importance of Social Security to Human Capital
}

\author{
Sui Dangchen ${ }^{1}$ Xingchen Liu $^{2}{ }^{*}$ \\ International Business School, Shaanxi Normal University \\ Xi'an 710062, Shaanxi, China
}

\begin{abstract}
The social security environment is an important factor restricting human capital. In recent years, scholars at home and abroad have conducted a lot of research on the relationship between social security and human capital. This paper summarizes the literature on the relationship between social security, human capital, social security and human capital by scholars at home and abroad and proposes that social security and human capital influence each other. China's social security and human capital should promote each other in development.
\end{abstract}

Keywords-Social security; Human capital; Social insurance; Income level

\section{DEFINITION OF SOCIAL SECURITY AND HUMAN CAPITAL}

The term "Social Security" first appeared in the "Social Security Act" promulgated by the United States in 1935. In the Social Work Dictionary published in the United States in 1999 social security was defined as: "The society provides income support to citizens in society who have difficulties in surviving the legal definition, such as the elderly, the sick, the sick or the unemployed." ILO definition Social security is: "Society provides protection to its members through a complete set of public policy support measures to prevent their economic earning capacity from entering into a difficult situation due to loss or greatly reduced causes of illness, maternity, workrelated injuries, unemployment, disability, and old age. To protect the medical care of members of society and to subsidize families with children (1984).

The theory of human capital was first proposed systematically by Theodore W. Schulz, the Nobel Prize winner in economics, and emerged as a new branch of economics. Jacob Minsel has for the first time constructed a complete model of human capital gains, elaborated the connection between human capital investment and income distribution, and also studied the role of on-the-job training in the development of human capital.

\section{THE RELATIONSHIP BETWEEN SOCIAL SECURITY AND HUMAN CAPITAL}

The connection between social security and human capital is a hot topic that has been continuously followed by many disciplines. Many scholars have published research arguments on this topic. For example, Gruber et al. (1999) believe that social security has a positive outlook on labor force retirement Role, [1] Sebastian Edwards et al. (2002) studied the relationship between social security reforms in Chile and the Chilean labor market. [2] Morten I. Lau Panu Poutvaar (2001) applied a simplified life cycle model to analyze the effects of different levels of social security on personal welfare, human capital investment, and labor supply. [3] Martin Barbie et al. (2002) believe that under the pay-as-go social security system where the funds are derived from the wage income of present and future generations, the labor orientation of the labor force is affected. This affects the development of human capital. [4]

In the existing social security research in China, the emphasis is to analyze the impact of social security on human capital at the present stage in China, and to discover the problems existing in the system, and then put forward reform measures. Yuan Zhigang and Sun Qixiang (2001) proposed the selection and reform of China's pension insurance system. [5][6] Based on the research of social security and human capital relations in the earlier years by scholars at home and abroad, and domestic scholars' discussion of China's social security funds, systems, reforms, etc., the current domestic research on the relationship between social security and human capital is mainly Starting from two major aspects are the positive effect of the social security system on human capital development and the positive impact of human capital on establishing a sound social security system.

\section{A. The positive effect of social security system on the development of human capital.}

The positive effect of social security on human capital is mainly through its main components, namely the formation and accumulation of human capital through social insurance, social assistance, and social welfare. At the same time, social security can also affect human capital through other means. Accumulation. 
1) The impact of social insurance on human capital.

Zhao Peipei (2014) proposed in the "Human Capital and Social Security" that social insurance can solve or predict the future and some uncertain risks of the workers. It can be seen as the investment of the human capital of the country, the unit, and the working people. [7]

Fernando believes that due to the uncertain future of human capital and the inability to diversify risk through capital market transactions, pension insurance provides an insurance mechanism to recoup all human capital investment rewards through pensions to stimulate human capital investment. [8]

Liu Yuanyuan (2005) pointed out in his article "Human Capital and Social Security" that employees with higher wages can receive a higher retirement pension after retirement, while higher wage levels depend on higher human capital. Therefore, the pension insurance model helps human capital investment. She also suggested that social security fees should be linked to wages and allowances so as to reflect the contribution of more work and more workers and to motivate the laborers and citizens [9].

\section{2) The impact of social assistance on human capital.}

Zhao Peipei (2014) proposed social assistance and charitable public welfare in the "Human Capital and Social Security" are guarantees for our own survival. For vulnerable groups, social assistance and charity charity are the goal preconditions and basic conditions for the formation of human capital.

Sui Dangchen and Peng Qingchao mentioned in the "Review on the Impact of Social Security on the Accumulation of Human Capital" that unemployment assistance provided assistance to the unemployed and people in need, so that their survival and family life could be maintained. This actually protected this part of the labor force. , and to create conditions for re-employment; education assistance can allow children of the right age to obtain the right to education, provide material and financial assistance for poor students, so that these people have a certain level of knowledge and technical skills; medical assistance is an investment in health, can let The recipient's body is guaranteed and more importantly, it reduces the probability that the poor will have no money to cure after illness, and lays the foundation for the development of human capital. [10]

\section{3) The impact of social welfare on human capital.}

Sui Dangchen and Peng Qingchao mentioned in the "Review on the Impact of Social Security on the Accumulation of Human Capital" that social welfare is conducive to raising the standard of living of children, the elderly, the handicapped, and economically disadvantaged families with weak living ability to a certain extent. And work capacity, which indirectly increase their human capital stock.
4) Other factors for the formation of human capital.

Zhang Yinghua and Du Yueping (2008) discussed the relationship between social security and the quantity of human capital and the quality of human capital in "Social Security and Human Capital Accumulation: The social security system encourages parents to pursue the quality of fertility rather than quantity and increase the level of human capital; social security also enables older workers to choose to retire earlier, and human capital decreases. The function of social security to compensate for risk losses has shifted to pre-prevention of risk Therefore, the core of social security management has shifted to human capital investment including health care. Third, social security and human capital migration have also been closely linked [11]

In summary, social security has both promoting and hindering effects on the accumulation and formation of human capital, but in general, the impact of social security on the accumulation of human capital is promoted

\section{B. The positive impact of human capital on social security.}

Not only will social security have an effect on the development of human capital, but human capital will in turn have a counter effect on social security, and they will affect each other.

Zhao Peipei (2014) puts forward that the investment in human capital from the perspective of human capital and social security is helpful to the improvement of social labor productivity and to higher income, so that the accumulation of social security funds can be increased. And even safeguard the effective operation of the fund

Liu Yuanyuan (2005) pointed out in the "Human Capital and Social Security" that the increase in human capital is largely due to the fact that more education has been received. The higher the level of education, the higher the level of human capital, and the more pensionable pensions that lead to retirement.

\section{REFORM PROPOSALS AND IDEAS}

Human capital investment can bring direct material economic benefits and huge social benefits. However, the recovery of profits is long, the risk is large, and the scale returns are obvious. However, they are intangible and cannot be directly observed. The establishment and improvement of the social security system has a great influence on the effect of human capital investment. In the evening, the social security system will not only produce talents, but also attract more talents and protect talents, thereby promoting social progress and development.

The relationship between human capital investment and social security can be said to be a kind of benign mutual assistance. Human capital investment mainly depends on the improvement of economic efficiency and the increase of total economic output; the goal of social security is to guarantee social fairness and justice. In the process of social development, it acts as a shock absorber. 
A. Improve the social security system, increase human capital investment, and maintain social stability.

In the period of rapid economic development of our country, the population is aging and aging, and the construction of social security system has been unavoidable. However, it is noted that social security can not only regulate the function of income redistribution, but also control the income gap to further expand. We can ensure the safety and profitability of human capital investment by providing social assistance, unemployment, endowment insurance and other types of insurance, so that we can continuously improve the social security reminder to increase the flow of labor resources and optimize the allocation of personnel, and thus achieve continuous economic growth.

\section{B. Increase social assistance efforts}

Poverty will lead to low human capital. Inadequate human capital will lead to lack of vitality. Poor people will not be able to steadily shake off poverty. Poverty means lack of infrastructure such as medical education. This is not conducive to the formation and development of human capital and forms a vicious circle that cannot escape poverty. . Therefore, in order to increase the quantity and quality of human capital, we must improve the social security system, not only providing a living guarantee that can sustain life, but also improving the quality and duration of human capital through education and medical assistance.

\section{Improve the social welfare of various groups}

The purpose of social welfare is to improve the material and spiritual living standards of members of society. The minor group is a human capital with great potential. To achieve long-term development, human capital must require the development of a policy system, and it is essential for the human capital investment of minors. The handicapped people with a lack of working ability are human capital with low quality, but it has been proved by practice that after targeted rehabilitation training, many disabled people can fully participate in social work as well as healthy people. This can not only improve the mental status of the handicapped. It is more conducive to them creating value for society. Therefore, strengthening human capital investment in children, disabled people, and other groups in the form of social welfare will inevitably increase the human capital stock of the entire society [13].

\section{Higher-level human investment guarantees economic development and promotes}

The welfare of the entire people through economic development. At present, China is in a period of rapid economic and social development and at the same time is the stage of coordinated economic and social development. The issue of food and clothing for our people is basically solved. With the development of the economy, the surplus of social products will increase year by year. At the same time, people's spiritual needs and higher levels of demand outside of material will continue to increase, and the need for people's all-round development will increase. The more urgent. The economic development is conducive to the development of science and technology, education, and society, providing assistance for them, and providing material conditions for the continued good development of the society, accelerating social development, and promoting the coordinated development of social economy to promote human capital to play an important role, thereby promoting the social security system. Good construction.

\section{CONCLUSION}

In short, the establishment of a sound social security system is a process that takes time and progresses steadily. It cannot be accomplished overnight. This requires us to earnestly consider the current socio-economic environment when investing in human capital, and we must not seek quick success. While fully considering the important role played by human capital in economic development, we must pay attention to the construction of a social security system to maximize its benefits.

\section{ACKNOWLEDGMENT}

About the author: Sui Dangchen (1963-), male, Linyi, Shaanxi, Professor of International Business School, Shaanxi Normal University, doctoral tutor, mainly engaged in public finance, social security and organizational behavior research;

Liu Xingchen (1992-), Male, Yulin, Shaanxi, Master graduate student of International Business School, Shaanxi Normal University, mainly engaged in social security theory and policy research.

\section{REFERENCES}

[1] Gruber, Jonathan and David A. Wise.1999Introduction and Summary: in Social Security and Retirement around the World, ed. Jonathan Gruber and D.A.

[2] Sebastian Edwards and Alejandra Cox Edwards. 2002. Social Security. Privatization Reform and Labor Market, the Case of Chile. NBER Working Paper, May, 2002: No. w8924.

[3] $\mathrm{Mu}$ Huaizhong. Research on Social Security Level in China [J]. Population Research 1997(1):48-57.

[4] "The Social Security System Reform and the Feasibility Study on the Levy of Social Security Tax" Task Force. The Basic Thinking of China's Social Security System Reform [J]. Economic Research 1994(10):10-18.

[5] Yuan Zhigang. Economic Analysis of China's Choice of Endowment Insurance System [J]. Economic Research 2001(5):13-19.

[6] Sun Yuxiang. "Empty Accounts" and Transition Costs [J]. Economic Research 2001(5):20-27.

[7] Zhao Peipei. Human Capital and Social Security [J]. Decision and Information, 2014 (7): 78-78.

[8] Fernando Sanchez Losada. Growth Effectsofan Un-funded Social Security System When there is Altruism and Human Capital [J]. Economics Letters, 2002, (69)

[9] Liu Yuanyuan. Human Capital and Social Security [J]. Theorists, 2005 (6): 50-51.

[10] Dang Dangchen, Peng Qingchao. Review on the Impact of Socia Security on Human Capital Accumulation [J]. Harbin University School Newspaper. 2015, 36 (12): 11-16.

[11] Zhang Yinghua, Du Yueping. Social Security and Human Capital Accumulation: An Overview of Research [J]. Economist, 2008, (5): 6167

[12] Li Zhifen. Analysis of the Effectiveness of Social Security Expenditure on Human Capital Cultivation [J]. Economic Research Guide, 2013, (25) 73-75. 